Научная статья

УДК 331

DOI 10.18101/2304-4446-2020-4-127-132

\title{
ТРАНСАКЦИОННЫЕ ЭФФЕКТЫ РАЗВИТИЯ БЛОКЧЕЙН-ТЕХНОЛОГИЙ
}

(C) Рыжкова Марина Вячеславовна

доктор экономических наук, профессор

marybox@inbox.ru

(C) Чиков Михаил Владимирович

кандидат экономических наук, доцент

chikovmv@mail.ru

Национальный исследовательский Томский государственный университет

Россия, 634050, г. Томск, ул. Ленина, 36

Благодарность: исследование выполнено при финансовой поддержке РФФИ в рамках научного проекта № 19-010-00352: Рынок цифровых платформ: сценарии преодоления потребительского сопротивления цифровизации.

Аннотация. В статье рассмотрены существующие институциональные подходы к анализу блокчейн-технологий. Блокчейн рассматривается как институциональная технология, которая порождает разнонаправленные трансакционные эффекты, причем разного качества и с разной трансакционной ценностью для пользователей.

Возможные трансакционные эффекты блокчейн-технологии могут состоять в способности мультипликативно изменять трансакционные издержки (для одних субъектов снижать, а для других, наоборот, увеличивать) и порождать для участников трансакций дополнительные институциональные результаты, в том числе при взаимодействии с другими институциональными технологиями (цифровыми платформами). Развитие цифровых технологий и, в частности, цифровых платформ создает новые типы трансакционных издержек - издержек сопротивления цифровизации и издержек цифрового сопротивления.

Трансакционные эффекты блокчейн-платформ могут состоять в том, что они могут позволить частично сгладить проблему сопротивления цифровизации, т. е. снизить трансакционные издержки первого типа. Но в то же время обострить проблему цифрового сопротивления из-за конфликтного сближения неформальных норм и формальных алгоритмов блокчейн-платформ. В зависимости от того, какой институциональный результат получает каждый конкретный пользователь, зависит его лояльность к этой институциональной технологии.

Ключевые слова: цифровые платформы; блокчейн; цифровое сопротивление; цифровизация.

\section{Для цитирования}

Рыжкова М. В., Чиков М. В. Трансакционные эффекты развития блокчейнтехнологий // Вестник Бурятского государственного университета. Экономика и менеджмент. 2020. № 4. С. 127-132. 
В современных экономических исследованиях все активнее обсуждаются последствия развития блокчейн-технологий для экономических систем. Будучи цифровой технологией, позволяющей за счет ведения распределенных реестров и алгоритмов консенсуса осуществлять децентрализованные трансакции между равноправными участниками, блокчейн порождают глубокую цифровую трансформацию. Выступая как альтернативный инструмент легитимации трансакций, он побуждает многие крупные корпорации трансформировать свои бизнесмодели и переходить на блокчейн-платформы [1], а правительства — активно принимать стратегические документы по регулированию национальных систем блокчейн [2].

Потенциал изменений, которые порождает данная технология для режимов функционирования современных рынков, настолько значителен, что влечет за собой и переформатирование существующих исследовательских парадигм, способных осмыслить ее как новую фундаментальную институциональную технологию [3]. Институциональная природа блокчейна не сводится просто к специфическому институту посредничества, она более сложна и неоднозначна. Поэтому можно согласиться с исследователями, которые считают, что традиционные подходы институционального анализа ограничены в понимании природы блокчейна, поскольку не способны описывать сложные и многомерные явления [4].

В попытке осмыслить теоретические и методологические основания блокчейн-технологий исследователи с разной степенью глубины раскрывают новые особенности их функционирования. Общим основанием в этих исследованиях является акцент на то, что они обеспечивают минимизацию трансакционных издержек, повышают эффективность экономических деятельности, устраняют необходимость посредников и фактически выступают альтернативным (рынку, фирме, государству) способом координации экономической деятельности [3].

Апеллируя к позиции сторонников теории трансакционных издержек, Д. П. Фролов в то же время указывает на ограниченность понимания институциональной природы блокчейна только с позиции минимизации трансакционных издержек и устранения посредничества. По его мнению, блокчейн-технологии не только снижают трансакционные издержки, но и способствуют увеличению трансакционной ценности для экономических субъектов за счет появления новых позитивных трансакционных эффектов на базе блокчейна [4]. Иными словами, речь идет о том, что институциональные технологии, обслуживающие процесс осуществления любой трансакции, помимо ее основного результата генерируют сопутствующий институциональный результат. И экономия на трансакционных издержках может быть лишь малой частью этого результата. Чтобы описать этот результат, следует раскрыть сложную природу блокчейна в логике порождаемых им трансакционных эффектов.

Сложность блокчейна как институциональной технологии состоит в том, что она вплетается в институциональную ткань современной экономики, трансформируя саму трансакционную механику (архитектуру трансакции) по многим формирующим основаниям. В соответствии с подходами институциональной теории в качестве таких оснований трансакции лежит перемещение ресурсов (в том числе информации) или санкционированных прав собственности [5; 6]. Следовательно, для осуществления рыночной трансакции необходимо понести, 
прежде всего, информационные издержки. Механика совершения трансакции предполагает, что ее участники не могут знать, с кем и на каких условиях она будет совершена, поэтому информация распределяется асимметрично и является очень дорогой [7]. В этой логике полная информация становится для участников трансакции бесконечно дорогой, поэтому контракты, которые они заключают для совершения сделки, должны быть неполными и оставлять некоторую степень неопределенности.

Как тогда осуществляется легитимация рыночных трансакций, т. е. как достигается консенсус между участниками сделки? Ключевым фактором здесь выступает доверие между участниками обмена и, прежде всего, к централизованному регистратору сделки (к государству как гаранту). Соответственно в экономических системах, где механизмы доверия слабо развиты (не эффективны), их поддержание обходится участникам трансакции очень дорого, поскольку вынуждает их предъявлять дополнительный спрос на посредников, вследствие чего трансакционный сектор разрастается.

С точки зрения теории трансакционных издержек развитие блокчейнтехнологий приводит к обратному сдвигу, когда централизованный метод достижения консенсуса заменяется распределенным подходом к консенсусу, основанном на бесплатном доверии к самому протоколу блокчейна и лежащим в его основе алгоритмам. Тем самым изменяется формирующее основание трансакции, поскольку блокчейн обеспечивает консенсус без доверия и потому способен устранить посредничество как таковое [3]. В этой логике лежащая в основе любой трансакции конфликтность, основанная на неполноте информации, также должна ослабевать.

Однако описанные изменения в трансакционной механике могут быть также неполными, поскольку, как полагает Д.П. Фролов, блокчейн вряд ли устранит полностью посредников. Скорее речь идет об их сокращении и усилении конкуренции между ними в части способности генерировать дополнительную трансакционную ценность [4]. В дополнение к этому тезису следует отметить, что блокчейн как институциональная технология создает дополнительный эффект не только для каждой отдельно совершаемой трансакции (например, на сделки по получению кредита), но и мультипликативно распространяется на смежные трансакции, повышая их качество (например, на сделки по купле-продаже товара через блокчейн-платформу и пр.) и сокращая трансакционный сектор экономики.

Таким образом, один из возможных трансакционных эффектов блокчейнтехнологии может состоять в способности мультипликативно изменять трансакционные издержки (для одних субъектов снижать, а для других, наоборот, увеличивать) и порождать для участников трансакций дополнительные институциональные эффекты, в том числе при взаимодействии с другими институциональными технологиями (цифровыми платформами).

Например, развитие цифровых технологий и, в частности, цифровых платформ создает новые типы трансакционных издержек - издержек сопротивления цифровизации и издержек цифрового сопротивления [8]. Первый тип издержек возникает из-за неготовности экономического агента (чаще всего из-за ценностных соображений) вообще взаимодействовать с цифровыми технологиями. Вследствие чего он несет дополнительные издержки взаимодействия, особенно в 
ситуации, когда институциональная инфраструктура подталкивает его к этому взаимодействию. Второй тип издержек возникает из-за «провалов» самих цифровых платформ и заложенной в них конфликтности, когда цифровая платформа, в том числе из-за сетевого эффекта, не способна оптимально скоординировать взаимодействия участников трансакций и создать равные для всех условия (например, равные условия доступа к платформе). Сбои в платформенном механизме может порождать несовершенство рейтинговых систем оценки репутации [9].

Построение цифровых платформ на базе блокчейн-технологий способно частично сгладить эти противоречия и сгенерировать дополнительные трансакционные эффекты. В частности, лежащие в основе цифровых платформ сетевые эффекты способны обеспечить прирост трансакционной ценности для каждого из участников через формирование новых механизмов доверия. Однако бесплатное доверие («сверхдоверие») к алгоритмизированным механизмам блокчейна, с одной стороны, и возможные «провалы» цифровых платформ, с другой стороны, могут потребовать формирования более сложных механизмов доверия в случае взаимодействия этих двух технологий.

Трансакционные эффекты блокчейн-платформ также состоят в том, что они могут позволить частично сгладить проблему сопротивления цифровизации, т. е. снизить трансакционные издержки первого типа. Блокчейн как технология, не требующая доверия, устраняет необходимость в мощных централизованных механизмах контроля, поскольку криптографически защищенные технологии являются безопасными от враждебных действий третьих сторон.

В то же время может обостриться проблема цифрового сопротивления, поскольку здесь может возникнуть дополнительная конфликтность из-за сближения неформальных норм и формальных алгоритмов блокчейн-платформ. Такие платформы вряд ли смогут полностью устранить проблему доверия, поскольку источники конфликтности могут быть разными. Конфликтность может состоять в том, что, предвосхищая потребности каждого конкретного пользователя блокчейн-платформы (в том числе используя технологии искусственного интеллекта, машинного обучения и пр.) и предлагая на этой основе персонализированные предложения, может возникнуть дополнительное цифровое сопротивление, основанное на страхе цифрового «сверханализа». Когда блокчейн-платформа знает о предпочтениях пользователя больше, чем сам пользователь знает о себе, то это может стать для него основанием к сопротивлению (например, преднамеренно искажать информацию о себе). Именно поэтому мы говорим о необходимости формирования специфических механизмов доверия в таких сложных и неоднородных институциональных системах.

Обобщающий вывод из анализа блокчейн-технологий может состоять в том, что, будучи очень сложной институциональной технологией, она порождает разнонаправленные трансакционные эффекты, причем разного качества и с разной трансакционной ценностью для пользователей. В зависимости от того, какой институциональный результат получает каждый конкретный пользователь, зависит его лояльность к этой институциональной технологии.

\section{Литература}

1. Rajiv L., Johnson S. Maersk: Betting on Blockchain. Harvard Business School Case 518-089, April 2018. 
2. Эльмурзаева Р. А., Скрыльникова Н. А. Подходы к государственному регулированию национальной системы блокчейн // Экономика и управление инновациями. 2019. № 4(11). C. 50-56.

3. Davidson S., De Filippi P., \& Potts J. Blockchains and the economic institutions of capitalism // Journal of Institutional Economics. 2018. 14(4). P. 639-658.

4. Frolov D. Blockchain and institutional complexity: an extended institutional approach // Journal of Institutional Economics. 2020. 1-16. https://doi.org/10.1017/S1744137420000272

5. Commons J. R. Institutional Economics // Its Place in Political Economy. Macmillan. New York, 1934. P. 58

6. Фуруботн Э. Г., Рихтер Р. Институты и экономическая теория. Достижения новой институциональной экономической теории: пер. с англ. / под ред. В. С. Катькало, Н. П. Дроздовой. СПб.: Издат. дом С.-Петерб. гос. ун та, 2005. XXXIV. С. 59.

7. Паркер Дж., Альстин М. ван, Чаудари С. Революция платформ. Как сетевые рынки меняют экономику — и как заставить их работать на вас / пер. с англ. Е. Пономаревой. М.: Манн, Иванов и Фербер, 2017. С.77.

8. Рыжкова М. В., Чиков М. В. Институциональная природа цифровых платформ // Вестник Бурятского государственного университета. Экономика и менеджмент. 2019. № 4. C. 72-80.

9. Querbes A. Banned from the sharing economy: an agent-based model of a peer-to-peer marketplace for consumer goods and services // Journal of Evolutionary Economics. 2018. 28(3). P. 641.

\title{
TRANSACTIONAL EFFECTS OF BLOCKCHAIN TECHNOLOGIES DEVELOPMENT
}

\author{
Marina V. Ryzhkova \\ Dr. Sci. (Econ.), Prof., \\ National Research Tomsk State University \\ 36 Lenina St., Tomsk 634050, Russia \\ marybox@inbox.ru \\ Mikhail V. Chikov \\ Cand. Sci. (Econ.), A/Prof., \\ National Research Tomsk State University \\ 36 Lenina St., Tomsk 634050, Russia \\ chikovmv@mail.ru
}

Abstract. The article discusses the existing institutional approaches to the analysis of blockchain technologies. Blockchain is considered as an institutional technology that generates multidirectional transactional effects with different quality and transactional value for users. Possible transactional effects of blockchain technology can manifest in the ability to multiplicatively change transaction costs (to reduce for some entities, and, on the contrary, to increase for others) and generate additional institutional results for transaction participants, and specifically in interaction with other institutional technologies (digital platforms). The development of digital technologies, and, in particular, digital platforms, creates new types of transaction costs - the costs of resisting digitalization and the costs of digital resistance. The transactional effects of blockchain platforms may partially diffuse the problem of resistance to digitalization, i. e. reduce transaction costs of the first type, but at the same time they may exacerbate the problem of digital resistance due to the conflicting convergence of non-formal norms and formal algorithms of blockchain platforms. The loyalty to this institutional technology depends on the institutional result of particular user.

Keywords: digital platforms; blockchain; digital resistance; digitalization. 
The reported study was funded by RFBR according to the research project № 19-01000352: Scenarios of overcoming the consumer digitalization resistance on the digital platforms market

Статья поступила в редакцию 23.10.2020; одобрена после рецензирования 30.10.2020; принята к публикации 30.10.2020. 